\title{
INTERNET ADVERTISING - A MARKETING TOOL SUPPORTING E-COMMERCE
}

\author{
P. Veleva* \\ Department of Informatics and Mathematics, Faculty of Economics, Trakia University, \\ Stara Zagora, Bulgaria
}

\begin{abstract}
The possibilities of Internet advertising as a modern marketing tool for supporting and developing ecommerce were explored based on a web survey. An example of a paid video advertising published in social media for a certain period of time is presented. Internet advertising was used by a small company as a marketing strategy to promote produced goods. According to Pay-to-click (PTC) criterion, a 60\% increase of interest by Internet users to the advertised product was reported. A significant increase in sales during the considered period was registered.
\end{abstract}

Key words: Internet advertising, e-commerce, PTC

\section{INTRODUCTION}

In recent years, the world and the Bulgarian economy have been changing rapidly, seeking a way to better and easier use of Internet services. In a well-developed society, companies and organizations are operating in increasingly global and intense competition on a market that changes daily in terms of technology, increased demands, tight deadlines, short life cycles and, above all, rising living standards. On the other hand, the Internet community is growing at an accelerated rate and the adaptation of business to this environment is of paramount importance for achieving good financial results. The fast-moving Internet leads to the exposure of the business to the various social markets, making them an indispensable part of their long-term development. Reaching as many target groups of users as possible is a priority for every entrepreneur and organization (1).

According to the Statistical Office of the European Communities, people who regularly use the Internet in Bulgaria are $63 \%$ of the

\footnotetext{
*Correspondence to: Petya Veleva, Department of Informatics and Mathematics, Faculty of Economics, Trakia University, Stara Zagora, Bulgaria, Tel: 0896601537; 042699 438, E-mail: pveleva@uni-sz.bg
}

population, which is about 4.5 million people. Again, according to their data, nearly 1.3 million Bulgarians in 2016 ordered goods or services on the Internet (2). This is about $30 \%$ of the Bulgarian population. For the past 2018, the growth of online trade in Bulgaria has jumped to $68 \%$, but it is still difficult to reach the levels of online trade for Europe. For the previous year, $86 \%$ of online sales were registered in the UK; for Sweden, $84 \%$ of online sales were registered, and for Denmark, Germany and Luxembourg $82 \%$ sales respectively (3).

Online marketing can be defined as methods and tools to influence consumers through advertising on the Internet (4). Internet advertising is a type of communication mix created by companies to inform, motivate and enhance the interest of consumers in the offered goods or services on the Internet. This is direct marketing, through which direct contact with the client is obtained. The goal is to achieve an immediate effect, which is expressed in the direct reaction of the consumers to the product, under the influence of advertising $(5,6)$.

At the moment, Internet advertising is a highvalue market that is increasing every day. The growing revenue from advertising space, especially through search engines such as 
Google, Bing, Yahoo, and social platforms such as Facebook, Instagram, Twitter, and others, are currently a strong incentive for the supply of goods and services. Free Internet services are getting more and the variety and volume of free information for Internet users is increasing. Internet service providers have the ability to monitor user behavior on the Internet, thus accessing a product or service reaches to a specific group of users $(7,8)$.

In order to achieve their goals, providers of goods or services on the Internet apply two types of advertising: an image advertisement designed to promote a company and increase the brand recognition or thematic advertisement, to attract a specific target group and to send a message to a specific target product $(1,9)$.

According to the report of Chavdar Dimov, Member of the Management Board of The Interactive Advertising Bureau for Bulgaria in 2018, the online market in Bulgaria registered a growth of $7.2 \%$ of the different types of Internet advertising compared to 2017 and reached 98.5 million BGN.

The biggest is the growth of mobile advertising $(7,8 \%)$ followed by the display $(6,7 \%)$ and video advertising (2\%) (10).

The world of internet advertising is in continuous movement. New and innovative online advertising methods are constantly being presented. There is a real market in the Global network, as virtually virtual users can at any moment become real users. Proper use of electronic advertising as an internet marketing tool, in turn, leads to attracting more customers, increasing sales, achieving a competitive advantage, and ultimately longterm, stable positive results for e-business (11, 12).

In this regard, the subject of research in this publication is internet advertising in terms of its ability to influence e-commerce. The task is to explore and analyze the opportunities offered by the Global network for advertising and the application of advertising as a marketing tool to support and develop ecommerce. For this purpose, an empirical study of the impact of Internet advertising on e-commerce was conducted through an electronic survey. The results obtained are analyzed and summarized using the Frequency Analysis method.
MATERIAL AND METHODS

1. A survey conducted by authorized (official) organizations for statistical researches

An investigation related to the impact of Information Technology on e-commerce published on the website of the National Statistical Institute (NSI) of the Republic of Bulgaria for the last five years.

\section{Company Hexed Props Ltd. as a subject of research}

The subject of research is a small start-up company, which, according to the data from the Commercial Register of the Republic of Bulgaria, deals with the production of requisites for re-productions and film productions, both at international level and on the territory of Bulgaria. The company carries out $90 \%$ of its online business (13).

\section{Data acquisition and data processing}

Two methods for collecting the information were used for the purposes of empirical research: a web-based survey implemented on the site of company Hexed Props Ltd. created through the Google forms and metrics provided by the company for paid video advertising distributed by Social media as a marketing strategy to promote a particular item produced by the company to increase sales. The main source of information and the respondent is the manager of company Hexed Props Ltd. Data are analyzed using the Frequency Analysis method, built into the Google platform, for marketing research.

\section{RESULTS AND DISCUSSION}

1. Results of statistical surveys of National Statistical Institute

According to NSI data shown in Figure 1, the growth of Internet consumption in the period 2014-2018 is observed. As shown in the graph, for each year thereafter, the increase in Internet usage for purchasing goods or services by $1,2 \%$ - $4 \%$ depending on the economic activity of the users.

Figure 2 presents NSI data showing that for a five-year survey, $10.8 \%$ to $39.0 \%$ of consumers want to shop in-store rather than on the Internet. The reason given is the willingness of users to become familiar with the product/service offered or the habit of visiting the shops. Other problems raised by National Statistical Institute for the period related to purchases over the Internet are: lack of skills or knowledge to shop over the Internet $(2.3 \%-8.5 \%)$; mistrust on payment methods and personal data security (2.6\% $6.2 \%)$; lack of information about receiving or returning goods $(3.2 \%-5.5 \%)$; absence of a payment card $(4.3 \%-6.2 \%)$, etc. 


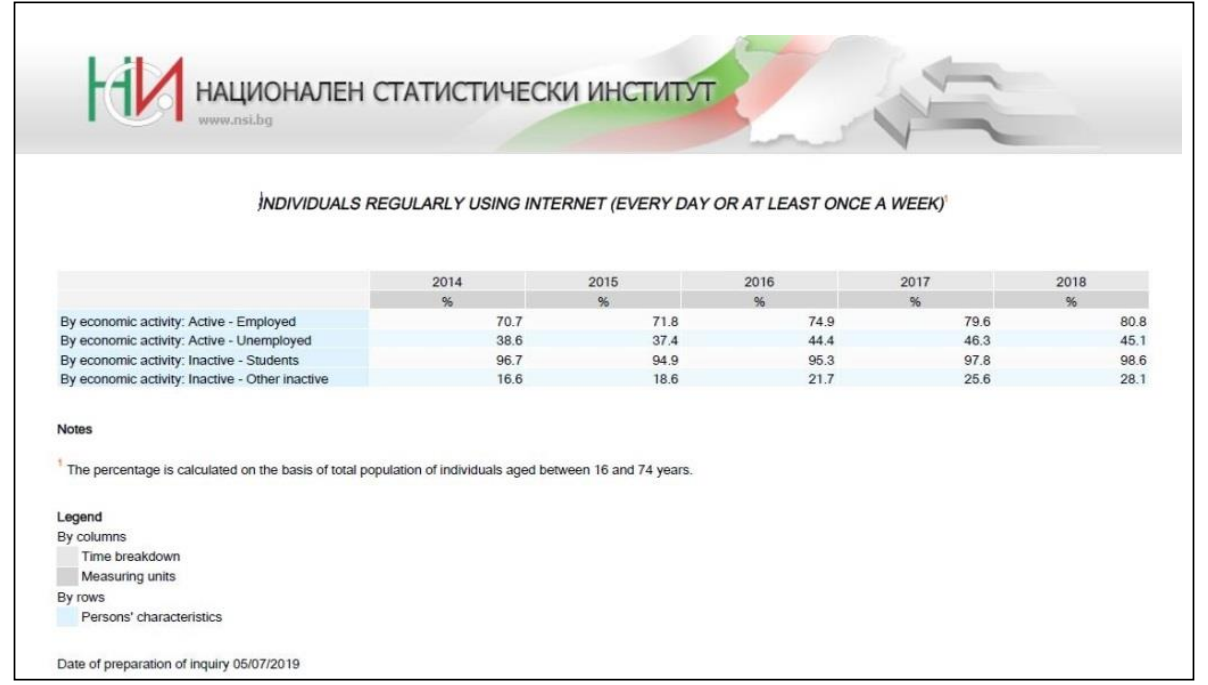

Figure 1. Individuals regularly using Internet (every day or at least once a week) (14)

In its study, National Statistical Institute highlights a number of difficulties and problems in purchases of goods and services over the Internet (Figure 3). One of the main issues mentioned by respondents for a five-year survey was that delivery time was longer than indicated (3.9\% to $11.7 \%$ ); wrong or damaged goods/services were delivered ( $2.4 \%$ to $3,8 \%$ ).
Other serious issues highlighted by the respondents are: difficulties in finding information concerning guarantees and other legal rights (3.2\% to $9.9 \%)$; technical damage to the website during order or payment $(1.9 \%$ to $4.8 \%$ ); the final cost is higher than indicated (1.3\% to $3.0 \%)$; problems related to Internet fraud $(0.3 \%$ to $3.7 \%)$, etc.

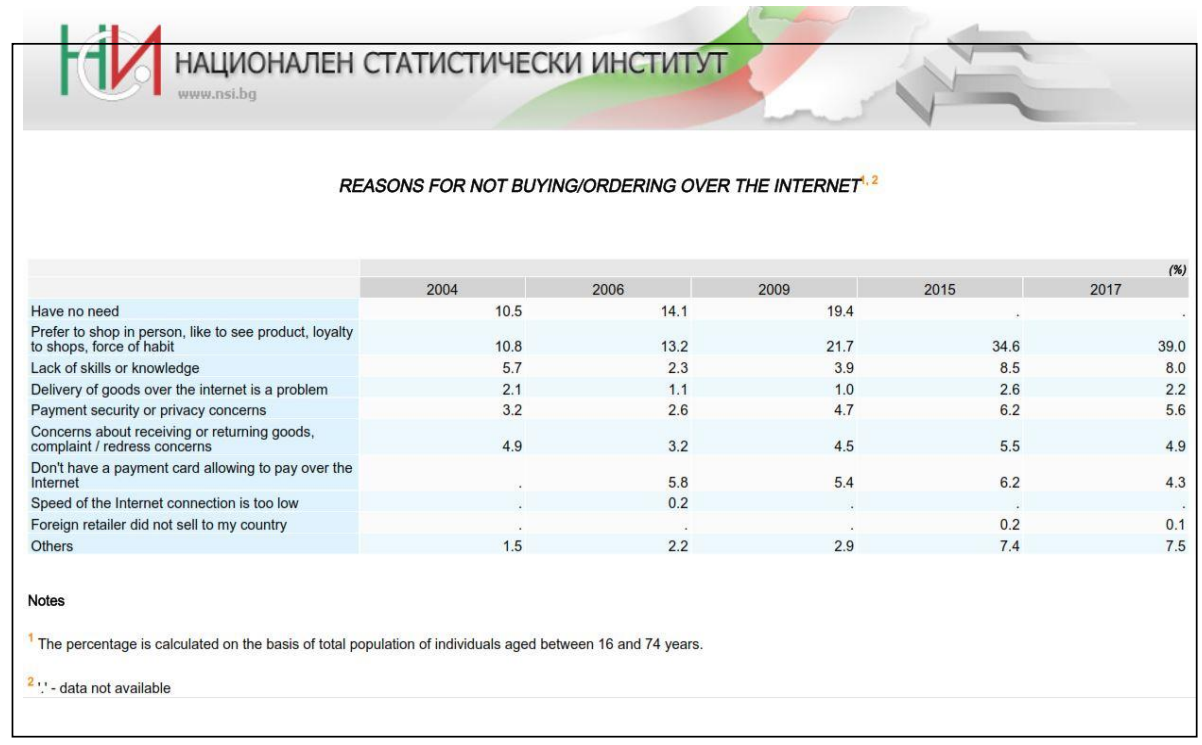

Figure 2. Reasons for not buying/ordering over the Internet (15)

Considering the geographical and demographic differences, it is normal for companies to use diverse and dynamic methods to increase sales, profits, and market leadership. Based on the data from the survey conducted by the National Statistical Institute, it can be concluded that the Internet is an efficient media and a good channel for the distribution of goods and services and a powerful tool for excellent internet marketing (6).

\section{Metrics provided by the company Hexed Props Ltd.}

Figure 4 shows the metrics provided by Hexed Props Ltd. for increasing the interest and purchase of a particular company item promoted in Social media via paid video advertising. The data covers the period 3-7 November 2018 (five business days), based on the so-called Pay-toclick (PTC) criterion according to which video advertising is sufficient for three seconds, in order to gain the user's attention and to report a profit to the advertiser. As can be seen from Figure 4, for the five-day periods in which the paid advertisement was active, a total of 85043 visits were reported, of which 33171 views matched the paid-to-click criterion. 


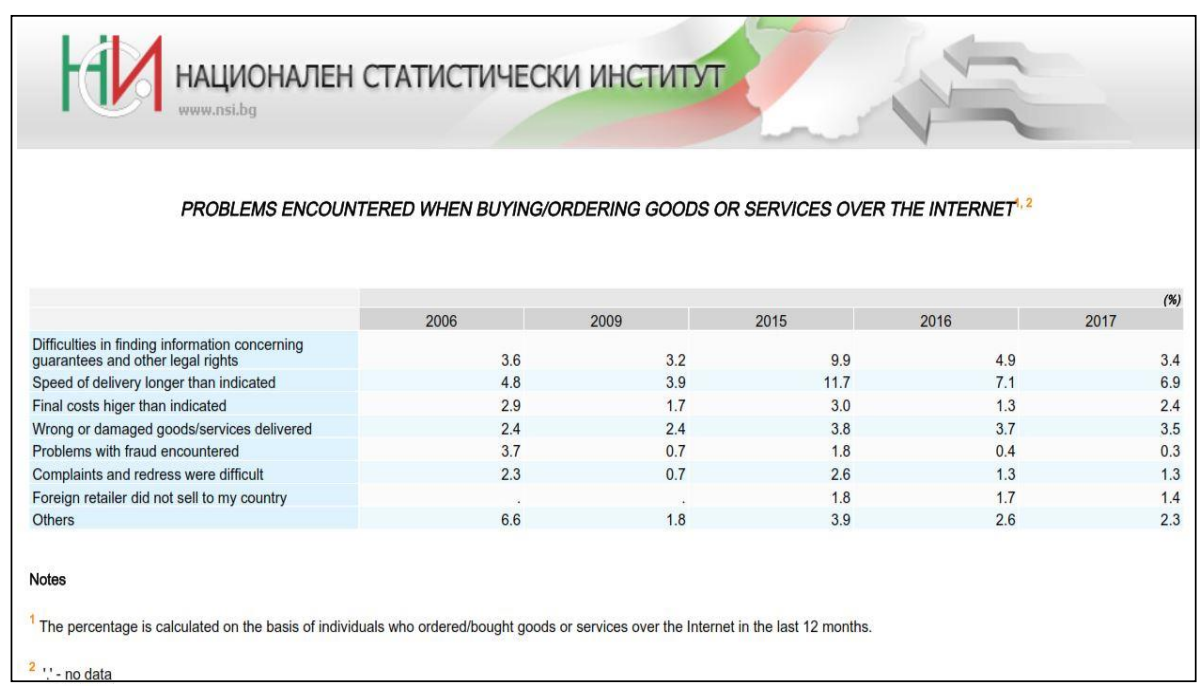

Figure 3. Difficulties encountered in ordering or purchasing goods of services over the Internet (16)

The group of users who watched the advertisement is from the USA, Germany, UK, Belgium, Italy, and Austria. The advertiser paid $\$ 20$ a day to promote it on social networks, and the distributor's profit was \$ 0.003 per video watch. The social media in which the paid video is distributed are Facebook, Instagram, and the Audience Network mobile app (Figure 5). As can be seen from the figure the largest percentage (about 60\%) are watching the video on Facebook, followed by Instagram (about 10\%) and mobile application Audience Network (about 2-3\%). Other ad views are most likely watched in other Social media but with a negligible percentage, which is why they are not reflected on the chart.

\begin{tabular}{|c|c|c|c|c|c|c|c|c|}
\hline Advertset & Detivery 0 & . & Ressults O & Reach 0 & $\operatorname{cost} \theta$ & Budget 0 & Amount spent 0 & Scheodule 0 \\
\hline 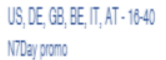 & Conpleted & & $\begin{array}{l}38,171 \\
\text { Therescond wites vients }\end{array}$ & 85,44 & 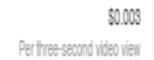 & $\begin{array}{r}52000 \\
\text { Daiy }\end{array}$ & 977.800097986 & 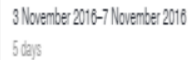 \\
\hline
\end{tabular}

Figure 4. Budgeting and metrics showing the consumer groups that watched the paid advertisement of the item produced by company Hexed Props Ltd.
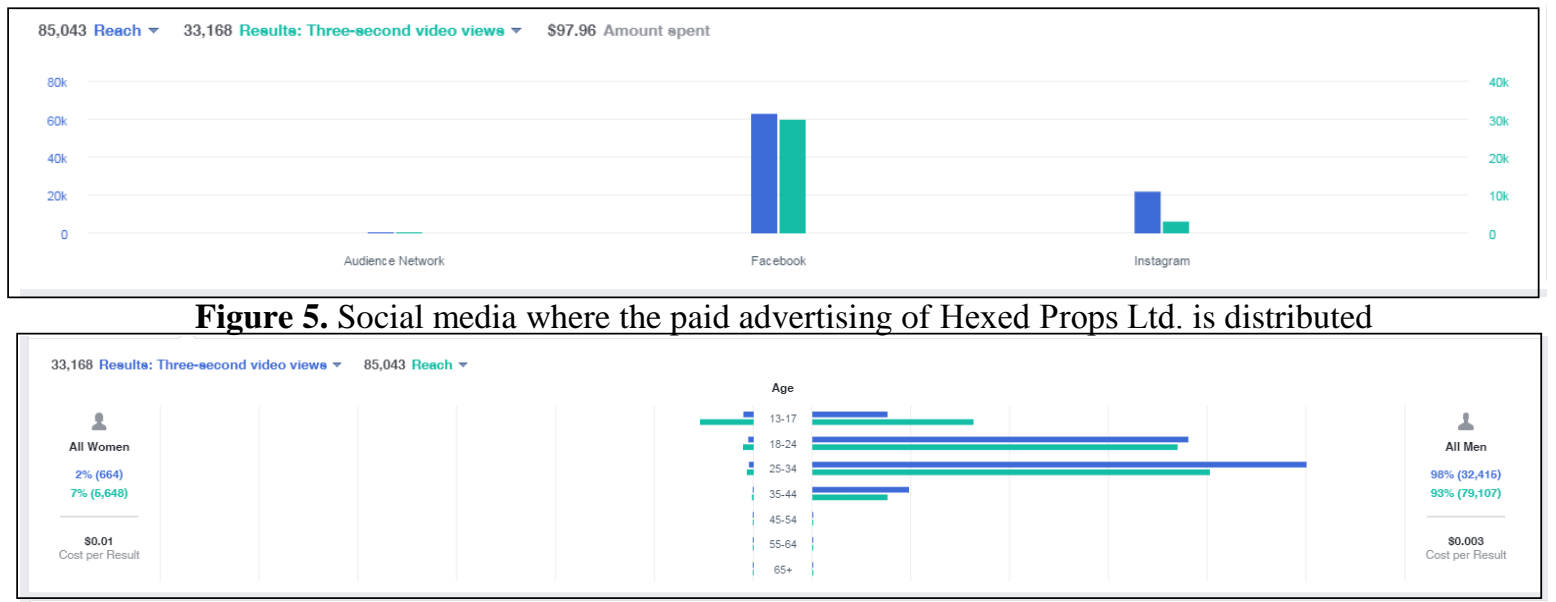

Figure 6. Distribution of the groups of users who viewed the advertisement of

Hexed Props Ltd. by age and gender

Due to the specificity of the advertised product, $98 \%$ of the users who viewed the advertisement are men and only $2 \%$ are women (Figure 6). The highest viewing rate of the video was recorded for the group of 25-34 years old, followed by the 18-24 years old 
group. Almost the same as the percentage of views in the age group 35-44 years old is the age group 13-17 years old. This is most likely (for the age group 35-44 years old) due to the lack of interest in the advertised product or the lack of funds for its purchase (for the age group 13-17 years old).

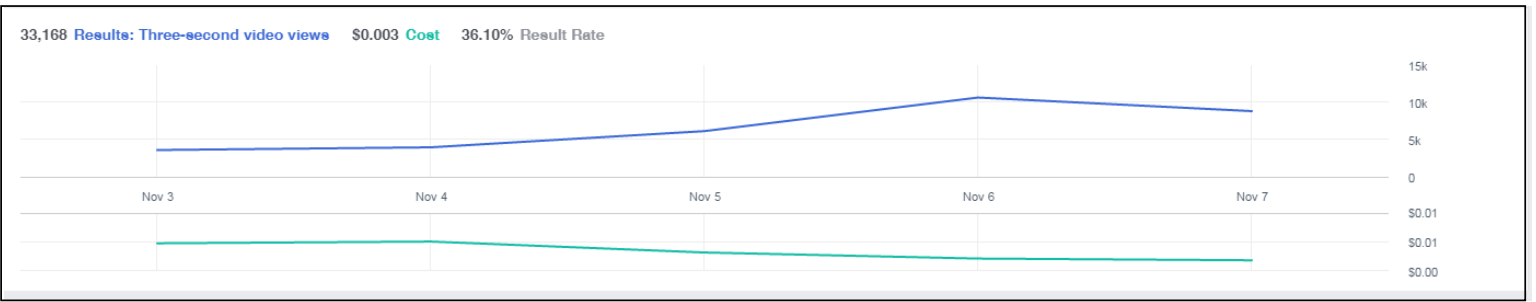

Figure 7. Distribution of the groups of users who viewed the video advertisement of Hexed Props Ltd. by day

Figure 7 reflects the growth of video advertising views over the paid time period. As can be seen from the chart, the highest number of advertising views is on the $3^{\text {rd }}, 4^{\text {th }}$ and $5^{\text {th }}$ day of the paid period, and on the $4^{\text {th }}$ day there is a sharp increase in watches, and on the $5^{\text {th }}$ day they begin to gradually decline. According to the metrics provided by the company for 5 days of paid advertising, 4 orders of the product at the promotional price were made.

The company sees this kind of digital marketing as a success, and in the future intends to focus on more active use of the Internet and various types of marketing strategies to promote its products.

\section{Description of the survey questionnaire}

A web-based survey was implemented for the purposes of the investigation, which was implemented on the website of Hexed Props Ltd. Within one month, a total of 110 people were questioned electronically. The poll was developed using the Google Forms platform. The platform offers the development of questionnaires tailored for both browser and mobile visualization. The platform allows automated data analysis, filtering responses according to survey needs, viewing individual responses, writing reports in PDF or XLS formats, and more.

Targeted questions were used to prepare the survey to ensure the accuracy of the information needed for the investigation. Their definition is consistent with the main hypothesis and objectives of this study. Access to the full set of questions can be obtained at:

https://docs.google.com/forms/d/11AMhw4aXV W3PNQXDaEucxsZBfJJ6D_Z5UQEQZcbU7XE /closedform

The results are summarized using the Frequency Analysis method. The number of answers to some of the questions does not coincide with the number of questionnaires, as most of the questions are open-ended i.e. it is possible to give more than one answer to a question.

In the study, $47.3 \%$ of men and $52.7 \%$ of women aged 20 to 65 were involved. The highest proportion of respondents were aged 20-40 $(81.9 \%)$. This result is understandable because it is the age group that is the fastest and easiest to get into using innovative technologies. From the results of the questionnaire, it is evident that the percentage of people with secondary education $(50 \%)$ prevails over people with higher education $(47.3 \%)$. Of the employed, $38.2 \%$ work in the private sector, $20.9 \%$ are employed in the public sector and $19.1 \%$ are students or have another form of employment, which shows that Internet advertising is accepted equally well by consumers different forms of employment.

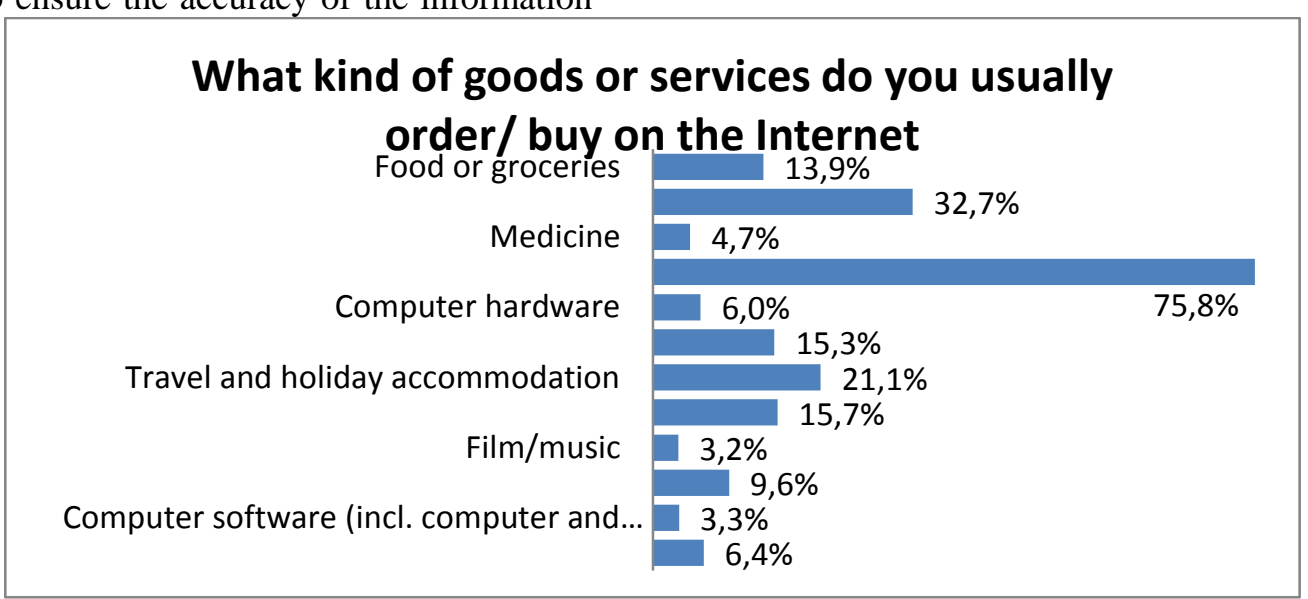

Figure 8. Type of goods or services ordered/bought on the Internet 
Figure 8 shows the type of goods or services ordered online as a result of Internet advertising. The figure shows that the largest percentage of respondents buy clothes or sports goods $(75.8 \%)$, followed by those buying goods for home $(32.7 \%)$, arranging trips and accommodation in hotels $(21.1 \%)$, purchased electronic equipment (15.3\%) and others.

Figure 9 shows the ratio between users who pay attention to Internet ads and those who find them irritating and boring. The results show that $28.2 \%$ of respondents only pay attention to some of the e-ads as they consider that other ads do not meet their user requirements for usefulness and awareness. It can be concluded that this disadvantage of internet advertising leads to the outflow of potential customers or customers looking for well-established brands. For them, the lack of sufficient information is, in most cases, crucial. At the other end, $24.5 \%$ of respondents (Figure 9) are paying enough attention to internet ads. For them, ads are a source of useful information about the advertised product/service. This is a group that knows exactly what it is looking for and thinks that the information in the ads is quite sufficient. There is also a group (22.7\%) who considers eads useful and informative, but does not pay enough attention to them. The survey shows that there are two other groups that use Internet banning programs (15.5\%) and advertisements that are irritating and boring $(9.1 \%)$. As can be seen from the chart, the percentage of these groups is significantly lower than the previous three groups.

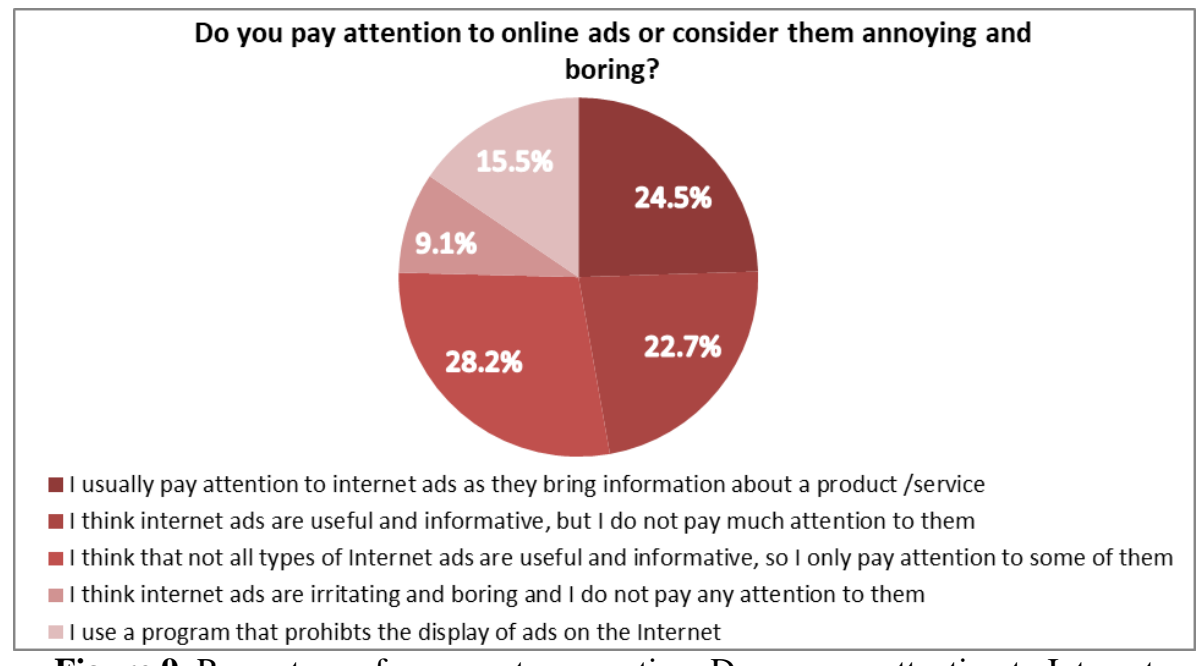

Figure 9. Percentage of answers to a question: Do you pay attention to Internet advertisement or do you consider them irritating and boring?

Figure $\mathbf{1 0}$ is shown the opinion of respondents about the influence of Internet advertising on e-commerce and consumer interest in a certain type of advertising. At about $70 \%$ of respondents think that Internet ads have a big impact on e-commerce, $22.7 \%$ think that online advertising has a little influence, and only $7.3 \%$ cannot judge. Concerning the interest in a given type of advertising, it can be seen from Figure $\mathbf{1 0}$ that the video advertisement is the most interesting (37.3\%), the mobile advertising ranked second $(22.7 \%)$, due to the fact that the majority of the population uses the latest generation (smartphone) phones where the distribution of video advertising is seamless. At about $13.6 \%$ of respondents think that Display ads are useful and informative and only 5.5\% have that opinion about Email advertising. There remains a group with a high percentage of respondents $(20.9 \%)$ who are not interested in internet advertising in general, no matter what form it is presented in. This is most likely the group of respondents who use ad blocking programs.

From the questionnaire survey, "Please indicate which of the e-commerce platforms you personally used as a result of internet advertising?" $75.4 \%$ of respondents said they were shopping online; every fourth (24.8\%) made an order through an electronic catalog, and $14.8 \%$ compared prices on different websites and only $6.7 \%$ of the respondents bought through an auction. The low utilization rate of the auction is most likely due to the fact that the service is more - less widespread. 


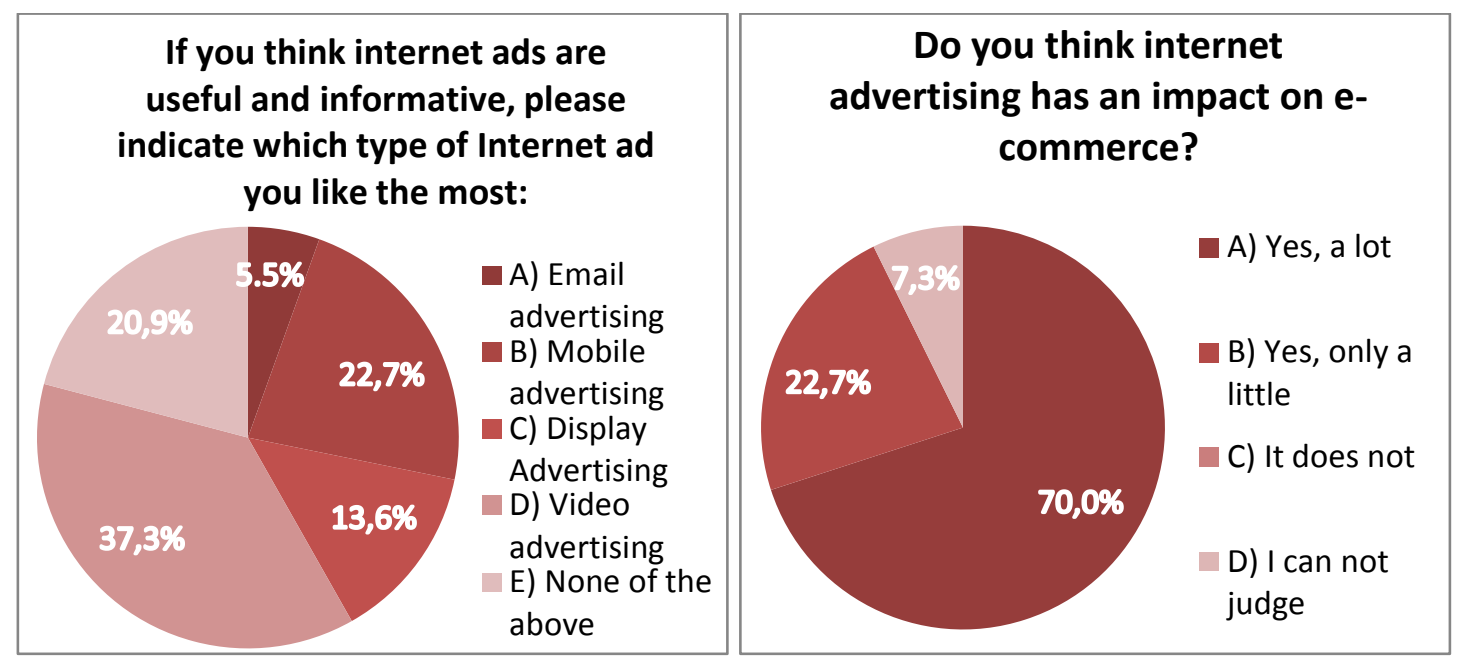

Figure 10. Influence of Internet advertising on e-commerce and consumer interest in a certain type of advertising

To the question, "Why do you motivate to shop online?" The respondents have highlighted reasons such as online shops are open 24 hours a day $(46.4 \%)$; there is no need to waste time traveling to shops $(40.6 \%)$, rare products are sought $(38.7 \%)$. Right away after the upper groups are ranked the respondents who consider that they have more choices than traditional shops (34.8\%) and only $10.4 \%$ of respondents believe that one of the reasons that motivates online shopping is the availability of loyalty programs.

Based on respondents' answers related to the frequency of shopping via the Internet it is clear that despite the great influence of the Internet advertising (70\%), the percentage of respondents who shop online is only $28.2 \%$. A significant percentage of respondents (33.6\%) answered that their purchases on the Internet are sometimes influenced by Internet ads and $24.5 \%$ answered that they rarely shop under the influence of the e-advertisements. Only $13.6 \%$ give an answer that they never shop on the Internet influenced by Internet ads.

According to $38.7 \%$ of respondents, as the most common obstacles, it can be said that the received product does not correspond to the product from the advertisement. Significant is the number of those who have not encountered obstacles when shopping online $(27.8 \%)$ and those who do not believe in the security of the site on the protection of personal data $(18.3 \%)$. Only $14.4 \%$ of respondents indicated as barriers to online shopping unclear warranty of purchased products and the difficulty of returning the purchased product. About 10.6\% who indicated as the reason for their refusal to shop electronically that their product had not arrived.
On the question, "What would motivate you to make more online purchases?" the respondents point to two main reasons: the lower delivery price $(48.7 \%)$ and discounts on online purchases $(40 \%)$. The better warranty scheme for goods purchased over the Internet is motivated by only $12.4 \%$ of respondents.

Regarding the question, "What expectations do you have for Internet ads?", respondents answered that their basic consumer expectations are related to current information on advertised products/services (42.7\%) and preferential offers $(34.5 \%)$.

In terms of income and amounts that consumers would have made for Internet purchases, it turns out that $40.9 \%$ have income from 401 to $1000(\mathrm{BGN})$ and $10 \%$ have revenues of $1001-1500$ (BGN). The number of those who refuse to answer what income they have monthly is high. There are trends $(55.5 \%)$ that, despite high income, consumers are willing to spend up to 200 (BGN). The percentage of those people who can not estimate how much money they spend on online purchases is $41.8 \%$. This is probably due to the fact that this group of consumers is shopping chaotically (within a month they can make several purchases, and next month none).

\section{CONCLUSIONS}

As can be seen from the survey, good Internet advertising with an appropriate vision can be a serious marketing tool for influencing both consumers and improving the image of companies and increasing their cash flows. Internet advertising as a marketing tool has an extraordinary impact on e-commerce and favors its development. Increasingly, purchases 
made through the global internet network are growing.

This, in turn, leads to an increase in the financial capital of companies and the consolidation of advertised products and services. Thanks to fast-growing technologies, even ads that are not informative enough about the product but are generally attractive are not passed by consumers.

The results of the survey confirm the statistics of the National Statistical Institute of the Republic of Bulgaria that a large number of consumers prefer to buy an advertised product or service from a shop as the most often cited reasons for this are the possibility of "touching" the product or the habit of buying from a shop. It is clear from the survey that there can be no close link between consumers who receive higher incomes and their propensity to spend more money on making purchases over the Internet. There is also such a group where, although people's incomes are low, they tend to make significant purchases on the Internet.

In the conducted survey many respondents recommend that the information about the advertised product/service be updated periodically; the information in the Internet advertisement reflects accurately and adequately the product/service; no misleading information; ads to be shorter, but made to attract attention immediately, and more.

In conclusion, we can say that the Internet is a successful digital marketing environment, including internet advertising is an appropriate means of helping and stimulating the development of e-commerce (17).

\section{REFERENCES}

1. Pateev, S., Fundamentals of the Internet Advertising, User Media Ltd., Sofia

2. Blitz bg, Eurostat revealed how many Bulgarians are shopping online, https://www.blitz.bg/ obshtestvo/ evrostat- razkri-kolko-blgari-pazaruvatonlayn_news486956.html, 2017.

3. Eurostat, E-commerce, Online shoppers \& e-purchases, https://ec.europa.eu/eurostat/cache/ infographs/ict/bloc-2.html, 2018.

4. ABV Soft, Internet marketing and advertising, abvsoft.bg/услуги/интернетмаркетинг-и-реклама

5. Genchev, E., Marketing, "VALDES - VV GM", Sofia, 2015.

6. Nencheva, I., E-commerce, http://edu.unisz.bg/book/14.SF_Elektronna.tyrgoviaINentcheva/, 2015.

7. Doganov, D., Durankev, D., Katrandjiev H., Integrated marketing communications, UNWE, 2003.

8. Internet Advertising - a New Dimension to Promote Business, https://help.superhosting.bg/ internetreklama-online-advertising.html, 2014.

9. How do we understand the ad correctly?, http://aktivnipotrebiteli.bg/статия/219/какда-разбираме-правилно-рекламата, 2006.

10. Dimov, Ch., Report of the Interactive Advertising Bureau for Bulgaria, https://iabbg.net/prouchvania/, 2018.

11.Tujarov, H. and Galabov, M., E-business, VTU,

http://www.tuj.asenevtsi.com/eBusiness/ Index.htm, 2013.

12.Goranova, P., Internet and web advertising - a new stage in the development of the advertising world. Economic Academy "D.Z.Tsanov", Svishtov, 2012.

13. http://hexedprops.com

14.https://infostat.nsi.bg/infostat/pages/reports/ result.jsf?x_2=708

15.https://infostat.nsi.bg/infostat/pages/reports/ result.jsf?x_2=1368

16.https://infostat.nsi.bg/infostat/pages/reports/ result.jsf?x_2=1367

17.Bardarov, E., The wrong context roundup change meaning of advertising, http://econ.bg/The Wrong-ContextRoundup-Change-Meaning-of-Advertising, 2012. 